\title{
CIDADE E URBANISMO
}

\author{
Jorge GASPAR
}

Centro de Estudos Geográficos. Universidade de Lisboa.

A Humanidade teve ao longo de milénios a CIDADE que, revestindo formas várias, correspondeu sempre a um ideal identificado como forma privilegiada de urbanização: a mudança de estilo de vida e dos comportamentos societais fazia-se através da vida na cidade e para a cidade (cf. GASPAR, 1987).

A medida que a "urbanização" aumenta para níveis que se aproximam da totalidade $(100 \%)$, a cidade vai perdendo sentido, vai deixando de responder às novas procuras (necessidades) e vai-se pulverizando/atomizando, ao mesmo tempo que aqui e além se procuram reconstituições da cidade que já não é ou se procura reduzir algumas "cidades" a museus...

$\mathrm{O}$ processo de urbanização tem sido tratado predominantemente numa perspectiva histórica, que recua até aos vestígios das primeiras cidades: mais de 6000 anos, 7000? 8000? Na realidade podemos até afirmar que o processo de urbanização se inicia com a agricultura e a produção de excedentes... embora a cidade, enquanto organismo e estrutura física, só apareça muito tardiamente.

Esse processo tem configurado, no tempo e no espaço, diferentes tipos de cidades: na forma, na função, no conteúdo social e cultural, nas dimensões política e simbólica.

Até há pouco tempo, urbanização era sinónimo de crescimento das cidades, de aparecimento de novas cidades. Foram sobretudo os sociólogos que começaram a questionar a assimilação dos dois conceitos (cf. ISHWARAN \& ANDERSON, 1964).

A primeira cidade em que entronca o nosso urbanismo, deixou-nos relatos, códigos, planos, instrumentos para planear: como construir uma cidade, como mantê-la e conferir-lhe grandeza. Aristóteles, no seu Tratado de Política, sintetizou tudo: de Sócrates a Hipodamus de Mileto.

É a cidade dos privilegiados: os cidadãos, que têm um comportamento urbano e direitos de que não prescindem.

E quem são os cidadãos?: os senhores do poder (político, militar, económico e religioso); os praticantes do espírito (filósofos, profetas, oráculos, sacerdotes...), os que se deleitam com todos os prazeres que só a cidade pode conferir: o conhecimento alargado, o erotismo, as delícias da comida dos quatros cantos do Mundo, o jogo e o desporto, a política, a economia e outros jogos de poder.

E a cidade vivia das trocas com o resto do Mundo, e do campo, ali à volta, que a abastecia. Para o exterior abria-se, pela navegação, pelo co- 
mércio, pelos contactos de civilização. Ao campo, restringia-lhe os direitos, dominava-o e explorava-o.

O Renascimento Urbano de finais da Idade Média é o Renascimento do Comércio. Afirma-se uma nova classe, de citadinos, os burgueses, que muitas vezes têm que ir viver para fora dos burgos, para os primeiros subúrbios. As cidades alargam o seu raio de influência, constituem-se em redes as ligas (de que a Hanseática foi o paradigma. Reforça-se também a articulação cidade-região.

Da promiscuidade da feira, pouco a pouco, a cidade vai promovendo a individualização funcional, com correspondência nas novas morfologias. Recupera-se o sentido do espaço público, a Agorafilia (DEWITTE, 1987) que agora é muito mais do que o espaço religioso das sés metropolitanas da primeira metade da Idade Média.

Os burgueses enriquecem e afeiçoam-se à cidade, que nalguns casos autonomizam, conferindo-lhe prerrogativas que os favorecem no confronto, na competição, com os congéneres.

As teias comerciais alargam-se pela terra e pelos mares e a componente negócio vai dominando a cidade, que protagoniza as grandes estratégias de poder da Burguesia, das Repúblicas Italianas aos portos da fachada atlântica.

Os contrastes de civilização, a difusão de inovações projectam-se na cidade, o que se traduz numa mais forte urbanização - a supremacia do urbanismo, enquanto estilo de vida é indiscutível e elementos da urbanidade difundem-se no mundo rural: as vilas renascentistas que, embora tenham mais expressão em Itália, rodeiam as principais cidades europeias da época, podendo mesmo afastar-se mais para a periferia, na procura dos mais belos e agradáveis enquadramentos paisagísticos. Das quintas apalaçadas, burguesas ou senhoriais, às grandes mansões edificadas por altos dignatários da Nobreza, do Clero, da Realeza, chegaram aos nossos dias numerosos exemplos que continuam a demonstrar o gosto de "casar" campo e cidade, numa época plural.

Entre a cidade do negócio e a cidade do trabalho poderíamos ter autonomizado outra, a cidade da ostentação do poder político absoluto - a cidade barroca. Mas corresponde a situações menos "universais" que as que "seleccionámos" e que em grande medida são cobertas pelos dois tipos iniciais.

A industrialização é o grande choque na cidade e ela só resiste mercê de grandes investimentos em infra-estruturas e após grandes confrontos sociais (1848, Comuna de Paris). Depois há como que um RENASCIMENTOํㅗㄴ,

${ }^{1}$ Os Novos Burgueses, que serão também os novos aristocratas, recuperaram a cidade, dando uma nova dimensão ao espaço público e ao espaço privado: o esplendor das estações de caminho-de-ferro - um símbolo da nova Era; o cuidado no tratamento dos jardins e dos passeios públicos, dando uma nova respeitabilidade à rua; os teatros "medem" o nível social 
mas também o aparecimento de um certo número de utopias que em grande medida trazem o germe do abandono da cidade. A fuga para o campo, da cidade linear de D. Arturo de Soria, à cidade-jardim que será sistematizada por Ebenezar Howard, depois de várias tentativas mais ou menos integradas em contextos políticos e económicos precisos, em que o elo de ligação reside no pressuposto idealista de que a urbanidade possível e necessária deveria integrar campo e cidade: por essas águas houve, recorrentemente, propostas de navegação, até aos nossos dias.

A cidade-jardim é o exemplo de maior êxito e adesão por parte de diferentes entidades e grupos sociais, tendo dado origem aos mais variados ersatz de cidade, desde os bairros "económicos" ou "sociais", aos bairros operários, de iniciativa pública ou empresarial ("o bairro na fábrica"), aos subúrbios das novas classes médias, ora sonhos ora pesadelos, que não deixarão de surgir até meados do século XX.

Mas o mito e a força imagética da cidade-jardim continua até ao final do século e emerge aqui e além sob variados programas e formas: desde alguns condomínios fechados de moradias, isolados e em banda, combinados com pequenos blocos de apartamentos, aos conjuntos assimiláveis das paisagens turístico-balneares, até a muitos parques temáticos. Nesta última categoria salientam-se as "Disneylandias" que, no plano da forma, são ainda uma manifestação da poderosa influência do ideal Howardiano.

A cidade da industrialização não respeita a ordem, o código aprofundado ao longo de milénios: as fábricas ocupam rossios ou baldios e lugares santificados (conventos, mosteiros e outras edificações da Igreja são nacionalizados e após venda em hasta pública servem para instalar indústrias ou equipamentos); as novas expansões urbanas razoiram cemitérios... que são substituídos por outros mais higiénicos, mais integrados na paisagem física, mas que perdem a aproximação ao quotidiano dos mortais.

É a cidade da total crença na tecnologia... e a história por um século vailhe dando razão: a electricidade e a energia nuclear libertam-na do carvão; o transporte sobre carris dá-lhe mobilidade para suportar o aumento de escala, o transporte subterrâneo "aguenta" o automóvel, mas não chega... Ainda num último forcing a cidade multiplica o espaço de circulação, das auto-estradas aéreas, aos túneis, do pneumático às telecomunicações...

Mas esta já é a cidade-negócio, em que os grandes negócios são feitos a partir do próprio corpo da cidade.

A cidade torna-se mercadoria, no seu todo e nas partes em que é possível descompô-la. A complexidade do fenómeno obriga à especialização e aparece mesmo uma nova disciplina: o marketing urbano, que é embebido na intervenção estratégica.

'(...continuación)

e cultural das cidades; as majestosas moradias e palacetes, alinhados nas novas avenidas dão outra dimensão aos "bairros novos", "convivendo" com edifícios de apartamentos para as emergentes classes médias. 
Das ruínas da cidade industrializada, constroem-se grandes projectos, uns de iniciativa pública, outros privada, mas o trend está na junção: partenariado público-privado é a nova linha de rumo para a renovação da cidade.

As grandes obras singulares ou os empreendimentos de grandes conjuntos geram valorização simbólica e financeira de segmentos discretos da cidade, podendo, nos casos de êxito da operação, constituir âncoras para uma revitalização do tecido urbano envolvente.

Através dos projectos de "marca", para os quais se convidam arquitectos de grande nomeada, promove-se a imagem da cidade, o que pode ter consequências positivas para os tecidos económico e social. Todavia, em vários casos desviam-se energias e recursos públicos de acções que teriam maior efeito na regeneração económica e social e, frequentemente, os grandes empreendimentos ficam aquém das expectativas ou não chegam mesmo a concretizar-se, total ou parcialmente.

Por outro lado, enquanto a cidade do trabalho cresceu à custa dos outros cidadãos que vivem no campo, mas no essencial têm a mesma cultura, a cidade negócio é obrigada a migrações menos integráveis... gentes de outros mundos... que não compreendem (nem poderiam...) ou não se submetem áquela lógica... São vítimas de outros negócios da cidade-negócio, por isso aumentam as tensões, os conflitos: invasão e fuga são componentes do mesmo processo de exclusão e marginalização.

As minorias, étnicas ou culturais, e segmentos sociais bem delimitados nos seus comportamentos, "enquistam-se" no território da cidade, sem possibilidade de integração e diálogo.

A cidade vai sendo cada vez mais um espaço descontínuo, nas suas dimensões territorial, económica e social.

Dá-se a desurbanização da cidade e a urbanização do espaço exterior que já não é campo. As componentes da cidade desagregam-se e instalam-se num território em que as componentes se articulam por redes de transporte e comunicação.

Note-se que a desurbanização não resulta só, como o pretendem alguns autores, da saída de população das cidades (cf. BERRY, 1976; FIELDING, 1986), mas também da sua "invasão" por habitantes de outras culturas, não-urbanizadas ou que acederam à cidade num contexto civilizacional muito diverso. Por outro lado, tão importante e decisiva como a saída das classes médias da cidade para os arredores, é a saída das empresas, dos serviços públicos, do comércio, das ofertas de lazer e, até, em muito casos, das unidades fabris.

Outra dimensão da desurbanização corresponde à "duplicação" do espaço de habitar, através do acesso à residência secundária. Enquanto no passado esta tinha um papel supletivo sazonal, progressivamente, foi ganhando outra força, primeiro enquanto espaço de evasão, aumentando a frequência do uso, para os fins de semana, que se tornam num ritual necessário. Mas para muitos é a residência citadina que se vai tornando secundária, projectando o lar para fora da cidade: numa situação que mais facilmente se 
assimila à concha mítica do refúgio, com o verdadeiro fogo do lar (a lareira...) e a animação da vida local. De facto, muitas das antigas vilas ou aglomerações balneares, replicam hoje a urbanidade tradicional, transformando-se em cada fim de semana em ersatz da cidade... onde os refugiados da grande metrópole vão "reviver" a memória urbana, fugindo ao acampamentolestaleiro em que se transformou a cidade, ou a sua percepção.

Nalguns casos, a cidade é, progressivamente, abandonada, manifestando-se alguma semelhança com o que se passou com os Maias antes da chegada dos europeus. Com uma agricultura baseada no milho e feita sobre queimadas, rapidamente esgotavam os solos agrícolas que geravam os excedentes que permitiam a existência das cidades. A solução encontrada foi o alargamento do raio em que abriam novas frentes de cultivo e, não conseguindo inovar nem nos transportes (desconheciam a roda...), nem nas técnicas de cultivo (fertilização, rotação, afolhamento...), foram obrigados a abandonar as cidades, o que desencadeou o declínio cultural, social e físico da civilização Maia.

Hoje, muitas cidades confrontam-se com um dilema: ou conseguem a reestruturação económica, com uma base produtiva robusta e estável, ou resta-lhes, para evitar a catástrofe, como por vezes parece estar iminente (Los Angeles, o final antecipado em Blade Runner...), ou a orientação para a especialização temática (histórica, cultural, puramente lúdica) para aproveitar as procuras crescentes no domínio dos lazeres.

De facto, algumas cidades não têm feito senão aprender com as experiências do Disneyworld, que tem sabido concretizar e valorizar a utopia do lazer, funcionando como santuário da religião superlativa que é a evasão, forma suprema do consumerismo. Michael Sorkin, antigo iluminante, dá-nos uma visão a um tempo fantástica e realista.

Em Orlando dias há com romarias de 100.000 pessoas e por ano são 30 milhões. Orlando "capital da transitoriedade", tem mais quartos de hotel que Chicago, Los Angeles ou mesmo Nova Iorque.

Outros santuários grandiosos atraem mais dezenas de milhões de fiéis: Disneyland na Califórnia, Tokio Disneyland e Eurodisney em Paris.

Mas o Mundo Disney é muito mais: lojas filmes, cassetes, livros, postais, pratos e copos de papel, roupa, brinquedos, objectos eróticos... Agora nos USA mesmo um canal de TV.

Há mais gente a conhecer o Mickey, do que a Jesus Cristo, Mao, Maomé ou Buda! (SORKIN, 1992).

A organização e a escala dos Disneylands são as da cidade-jardim (SORKIN, 1992, 215). A sua localização é equivalente à dos novos parques de escritórios ou grandes centros comerciais periféricos. Faz parte dos espaços das novas urbanidades, mas é a única que procura replicar a cidade.

A Disneyland representa a sintese, mima a cidade que entretanto se pulverizou: nos "condomínios exclusivos", nos parques de escritórios, nos "super-malls", e no que progressivamente vão sendo as ruínas da antiga cidade... onde habitam os invasores-prisioneiros e os guardas protegem os símbolos mais fortes do Estado e da Cultura: o Parlamento, o Governo, os 
Museus, os Teatros.

Os aeroportos constituem outra componente do mundo pós-citadino, organizam-se, no entanto, à imagem de cidades planeadas: o de Kennedy ainda à imagem da cidade dos mundos de vizinhança...

O mais recente de Hartsdale (Atlanta), é a ideia da cidade do futuro, (que talvez nunca se realize, porque é muito cara...), mas é possível num aeroporto de grande rendibilidade: com as pessoas a serem movimentadas automaticamente, sem necessidade de veículos, de tráfico, tudo gerido (anunciado) por uma voz que começou por ser feminina, mas como soava a pouca autoridade, foi substituída por uma voz sintetizada, a voz com que imaginamos o futuro ${ }^{2}$ (SORKIN, 1992).

Os condomínios privados vão crescer e vão aumentar em complexidade o controle que será progressivamente mais automatizado. O Super Big-Brother controlará as entradas, saídas e todos os movimentos intermédios, na medida em que o utente/residente terá que utilizar sempre um cartão magnetizado, que o identifica e cujo registo fica na memória central: da garagem, ao hall, ao corredor X24, para aceder ao Bar (Z2), à piscina, à sauna ou para accionar o seu terminal inteligente que, por sua vez, lhe comunica as mensagens registadas... ou o comportamento de todos os instrumentos/robots auxiliares do trabalho doméstico.

A cidade deixa de ter segredos, insegurança, novidades... tudo está programado e já não é a cidade...

Mas a cidade temática não se limita aos países ocidentais, nem só a países ricos. Nova Delli tem agora também um parque, que segundo o Secretário de Estado do Turismo da União Indiana, se justifica pois "like all big cities, Delli is getting polluted. It is getting choked with people. "People need amusement and clean air" (N.Y. Times, 10/02/90, citado por SoRKIN, 1992).

Por outro lado, as cidades históricas tendem a especializar-se e a organizar-se segundo a mesma lógica da cidade temática: aqui os temas são a história, a cultura e a imagem que se faz da cidade. A tão criticada museificação das cidades que, perdidas as suas bases económicas tradiconais, sobrevivem pela exibição das suas memórias, dá lugar à animação dos eventos culturais, que se concentram em períodos específicos.

Por vezes, não temos a estação deste ou daquele espectáculo, desta ou daquela feira, mas temos a estação desta ou daquela cidade. Veneza é Veneza no Carnaval e no Festival. No Verão é turismo, no tema Veneza! No resto do ano é um museu calmo e visitável.

$\mathrm{Na}$ multiplicação dos enfoques temáticos, nas cidades históricas, a todos sobreleva a sensação forte de viajar no tempo. Daí a grande preocupação do cenário e a afirmação da ideologia da protecção do património. Valor autónomo e englobante é o das muralhas: a conspiscuidade de um bom

\footnotetext{
${ }^{2}$ Quando os primeiros astronautas chegaram à Lua, pareceu-nos tudo tão esperado... o som, as vozes, de há muito que nos eram familiares...
} 
muro envolvente cria a melhor ambiência para entrar o limiar do tempo.

A cultura é outro tema maior, que em si mesmo pode constituir um eixo de hierarquização urbana, tal é a sua crescente universalidade no mundo das cidades. Fala-se já nas indústrias da cultura, o que não deixa de ser sintomático e ilustrativo da evolução do conteúdo económico e funcional que se observa em muitas cidades. O peso relativo das actividades culturais ou induzidas por estas aumenta por toda a parte, das mais pequenas vilas às maiores metrópoles.

Paris, propriamente dita, nos dois últimos decénios, refinou-se enquanto cidade de cultura e de história. Mais do que capital cultural do mundo francófono, Paris afirma-se como a capital do consumo e do lazer cultural: uma verdadeira cidade temática. O sinal mais espantoso desta evolução é o recém criado imposto de pernoita, que qualquer visitante é obrigado a pagar; além dos impostos incluídos em todos os consumos que faz e dos pagamentos e tarifas relativos a bens e serviços que adquire, o turista é obrigado a pagar como que um direito de entrada no grande parque de diversões.

É sintomático que hoje, sempre que se empreende uma operação de reabilitação urbana, tão ao gosto actual (valor e espírito do tempo), o arquitecto, o urbanista, quando se confrontam com a questão "mas que vamos fazer com isto?" (um quarteirão, um antigo quartel, um antigo palácio, um templo desactivado...), a resposta seja, quase invariavelmente, um equipamento para actividades culturais. Que temas têm entusiasmado mais lisboetas e portugueses em matéria de intervenção urbana? - O Centro Cultural de Belém e a EXPO 98. Já que não podemos ter o Rato Mickey!

História e cultura são dois ingredientes fundamentais na afirmação da cidade pós-moderna e bem explicitados em múltiplas operações de marketing urbano. Os chamados planos estratégicos têm sido veículos privilegiados de transporte das mensagens que procuram dar maior "competitividade" às cidades pela valorização do seu passado, presente ou reconstituído, e dos seus acontecimentos culturais. Alguns autores reflectem e escrevem sobre a festivalização das políticas urbanas (VENTURI, 1994).

A reconstrução da cidade sobre as ruínas da era industrial faz-se, por um lado, enaltecendo a urbanidade aparente do núcleo histórico - potencializando as dimensões histórica e cultural; e, ao mesmo tempo, pulverizando a cidade, em novas formas urbanas, segregadas e segregadoras, por um vasto espaço envolvente da cidade antiga.

A tematização da cidade é correlativa do aparecimento dos parque de escritórios e dos centros comerciais no cruzamento de auto-estradas metropolitanas; as novas áreas residenciais e de lazer, ribeirinhas ou periurbanas são novas formas do urbanismo desarticulado e segregado.

Os elementos constitutivos da urbanidade dispersavam-se: o habitar, o produzir, o consumir, o lazer, o fazer política, ocupavam espaços específicos e individualizados, não no interior da cidade, mas num espaço topológico, que não é possível reproduzir na continuidade/contiguidade de uma peça da cartografia tradicional. 
O rápido desenvolvimento das telecomunicações, da informação veio ao encontro das tendências activas no novo processo de estruturação urbana, acentuando, facilitando ou estimulando a eclosão de novas formas, novos comportamentos e novos valores. Em tão pouco tempo que decorreu desde o aparecimento do fax, do telemóvel e da emergência dos sistemas integrados de redes digitais (ISDN), já se escreveu muito em contradições e hoje mesmo os que mais longe conseguem olhar o futuro, não arriscam como há uma década.

Cresce a incógnita sobre os espaços que o homem vai produzir, sobre as margens de liberdade e as restrições à intervenção no sentido de continuar uma certa cultura material.

É cada vez maior a interrogação sobre o futuro da cidade e do urbanismo.

\section{REFERÊNCIAS}

DewitTe, J. (1987): «Eloge de la Place - Camillo Sitte on 1'agoraphilie», in La Ville Inquiète, pp. 151-177, Gallimard, Paris.

GASPAR, J. (1987): «Do Pelourinho ao Centro Comercial» in Povos e Culturas, $\mathrm{n}^{0} .2$, pp. 243-259, Lisboa.

ISHWAEAN, K. \& ANDERSON, N. ED. (1964): Urbanism and Urbanization, E.J. Briell, Leyde.

SORKIN, M. (1992): «See you in Disneyland» in SORKIN, M. (Ed.) Varia tions on a Theme Park, pp. 205-232. The Noonday Press, Nova Iorque.

VENTURI, M. ED. (1994): Grandi eventi La festivalizzazione della politica urbana, Il Cardo, Veneza. 
En la nota del Prof. Gaspar (Cidade e Urbanismo, pp. 165-172) no se incluyó por error el siguiente cuadro:

\section{CIDADE E URBANIZAÇĀO}

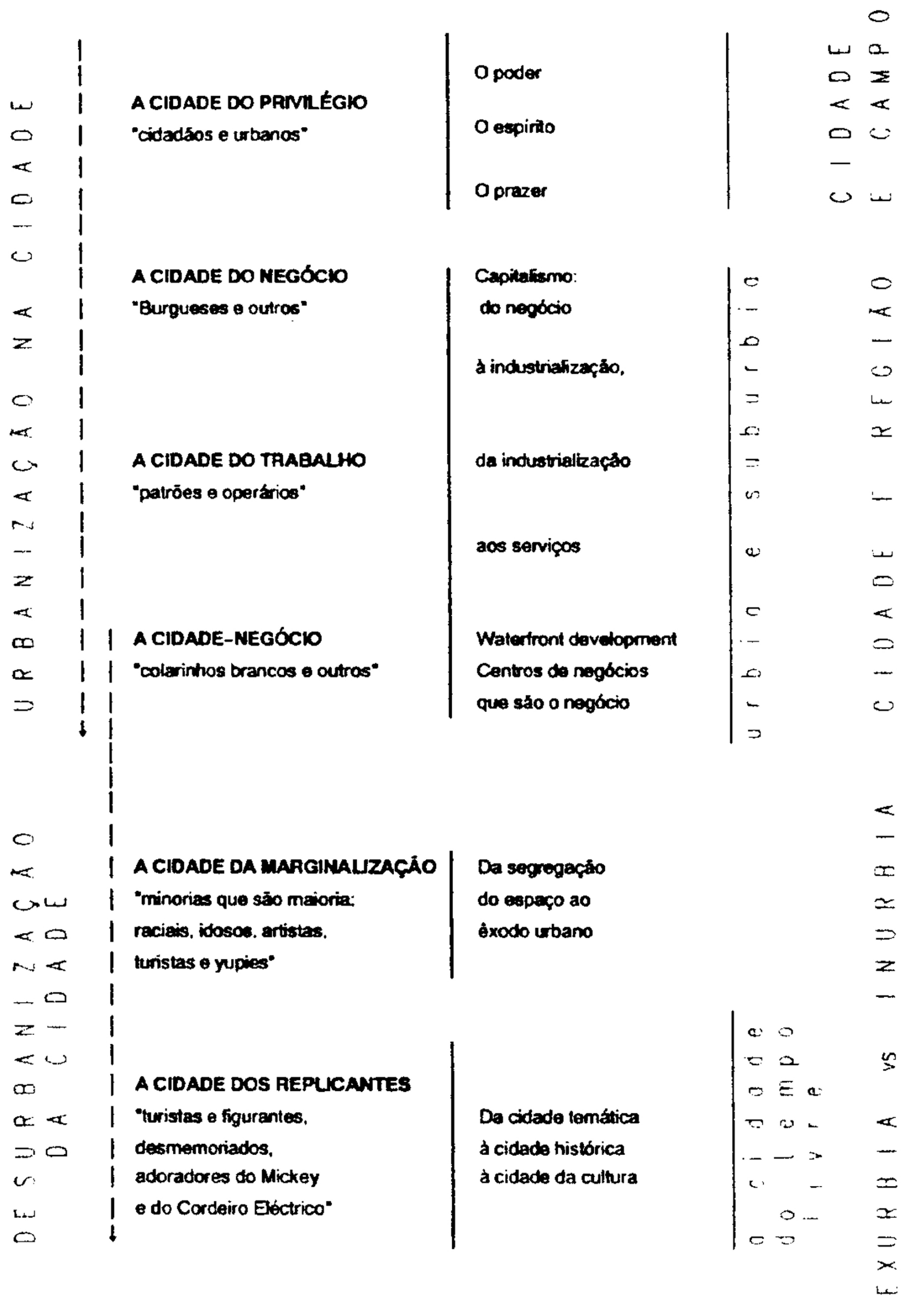

